\title{
Symbiont-Driven Male Mating Success in the Neotropical Drosophila paulistorum Superspecies
}

\author{
Daniela I. Schneider ${ }^{1,5} \cdot$ Lee Ehrman ${ }^{2} \cdot$ Tobias Engl $^{3} \cdot$ Martin Kaltenpoth $^{3} \cdot$ Aurélie Hua-Van $^{4} \cdot$ Arnaud Le Rouzic $^{4}$. \\ Wolfgang J. Miller ${ }^{1}$
}

Received: 6 June 2018 / Accepted: 30 October 2018 / Published online: 19 November 2018

(C) The Author(s) 2018

\begin{abstract}
Microbial symbionts are ubiquitous associates of living organisms but their role in mediating reproductive isolation (RI) remains controversial. We addressed this knowledge gap by employing the Drosophila paulistorum-Wolbachia model system. Semispecies in the $D$. paulistorum species complex exhibit strong RI between each other and knockdown of obligate mutualistic Wolbachia bacteria in female D. paulistorum flies triggers loss of assortative mating behavior against males carrying incompatible Wolbachia strains. Here we set out to determine whether de novo RI can be introduced by Wolbachiaknockdown in D. paulistorum males. We show that Wolbachia-knockdown D. paulistorum males (i) are rejected as mates by wild type females, (ii) express altered sexual pheromone profiles, and (iii) are devoid of the endosymbiont in pheromone producing cells. Our findings suggest that changes in Wolbachia titer and tissue tropism can induce de novo premating isolation by directly or indirectly modulating sexual behavior of their native $D$. paulistorum hosts.
\end{abstract}

Keywords Wolbachia $\cdot$ Drosophila $\cdot$ Reproductive isolation $\cdot$ Premating isolation $\cdot$ Pheromones

Edited by Yong-Kyu Kim.

Electronic supplementary material The online version of this article (https://doi.org/10.1007/s10519-018-9937-8) contains supplementary material, which is available to authorized users.

Wolfgang J. Miller

wolfgang.miller@meduniwien.ac.at

1 Department of Cell and Developmental Biology, Center of Anatomy and Cell Biology, Medical University of Vienna, Schwarzspanierstrasse 17, 1090 Vienna, Austria

2 Natural Sciences, State University of New York, Purchase College, Purchase, NY, USA

3 Department for Evolutionary Ecology, Institute for Organismic and Molecular Evolution, Johannes Gutenberg-Universität, Mainz, Germany

4 Évolution, Génomes, Comportement, Écologie, CNRS, Institut de Recherche pour le Développement, Université Paris-Sud, Université Paris-Saclay, 91198 Gif-sur-Yvette, France

5 Present Address: Department of Epidemiology of Microbial Diseases, Yale School of Public Health, New Haven, CT 06511, USA

\section{Introduction}

Potential impacts of microbial symbionts as drivers of host speciation have been discussed frequently (Bordenstein et al. 2001; Jaenike et al. 2006; Telschow et al. 2007, 2014; Brucker and Bordenstein 2012; Gebiola et al. 2016), but their broader evolutionary significance fostering speciation remains controversial (Brucker and Bordenstein 2013, 2014; Chandler and Turelli 2014; Turelli et al. 2014; Najarro et al. 2015; Leftwich et al. 2017), and standard models of speciation commonly disregard such impacts (Coyne and Orr 2004; Brucker and Bordenstein 2012; Miller and Schneider 2012). Several theoretical models have nominated the maternally transmitted reproductive tract endosymbiont Wolbachia as a candidate worthy of consideration (Telschow et al. 2007, 2014). The $\alpha$-proteobacterium Wolbachia is arguably the most prevalent intracellular invertebrate infection on the planet, infecting as many as $40 \%$ of all terrestrial arthropods (Zug and Hammerstein 2012). Wolbachia have attracted attention as participants in arthropod symbioses because they successfully manipulate host biology in manifold ways, ranging from reproductive parasitism like cytoplasmic incompatibility (CI), male killing, feminization and 
parthenogenesis to nutritional supplementation, fecundity and protection from pathogens and parasites (Werren et al. 2008; Teixeira et al. 2008; Brownlie et al. 2009; Fast et al. 2011; Moriyama et al. 2015). Although Wolbachia are mainly found as facultative endosymbionts in most insect hosts (Martinez et al. 2015 and references therein), they also can evolve fixed obligate associations such as in the parasitoid wasp Asobara (Dedeine et al. 2001), bedbugs (Hosokawa et al. 2010), or neotropical fruit flies belonging to the Drosophila paulistorum species complex (Miller et al. 2010).

In the latter case, this superspecies is under incipient speciation in the wild and consists of six semispecies (Dobzhansky and Spassky 1959), named Amazonian (AM), Andean Brazilian (AB), Centroamerican (CA) Interior (IN), Orinocan (OR) and Transitional (TR), expressing strong RI at the pre- and postzygotic level in inter-semispecies crosses (reviewed in Ehrman and Powell 1982). As recently found they all carry different loads of obligate mutualistic but distinctive Wolbachia strains (Miller et al. 2010), which can cause strong cytoplasmic incompatibilities (embryonic mortality) plus complete hybrid male sterilities in reciprocal crosses between different semispecies in the laboratory. Because Wolbachia are obligate endosymbionts in this system, no uninfected flies can be generated (Ehrman 1968; Kernaghan and Ehrman 1970; Miller et al. 2010) to test for classic bidirectional CI as feasible in facultative symbioses such as in Culex pipiens mosquitos (reviewed in Werren et al. 2008). The association between the obligate Wolbachia symbiont (earlier designated Mycoplasma-like-organisms, MLOs; reviewed in Ehrman and Powell 1982) and the induction of postmating isolation, however, is based on earlier and recent findings that hybrid lethality and male sterility are partly reversible upon mild antibiotic or heat treatments of the parents before mating (Ehrman 1968; Kernaghan and Ehrman 1970; Miller \& Schneider, unpublished).

In two earlier publications, Dobzhansky and collaborators (Dobzhansky and Pavlovsky 1966, 1971) observed the spontaneous evolution of de novo postmating isolation as some lines, which were originally fully compatible with the Orinocan reference strain $\mathrm{O} 11$, were no longer compatible with this semispecies or any other semispecies of $D$. paulistorum. This resulted in occurrence of high embryonic $F_{1}$ mortality and complete male hybrid sterility, presumably because of drift and isolation in these lines in the laboratory. However, the role of endosymbionts on the formation of premating mechanisms has been less studied in the past (Dobzhansky and Pavlovsky 1966, 1971; Miller et al. 2010). Importantly, in facultative symbioses, where Wolbachia has not reached fixation in their natural hosts as in D. melanogaster or $D$. yakuba group species, the authors did not detect any Wolbachia effect on premating isolation (Sharon et al. 2010; Arbuthnott et al. 2016; Cooper et al. 2017).
This current study is based on the recent observation that $D$. paulistorum semispecies show strong premating isolation through female mate choice for intra-semispecific (homogamic) males (Fig. 1A, left panel). Such behavior is lost upon Wolbachia-knockdown in females, i.e., significant titer reduction but not clearance, resulting in random mating between per se incompatible, heterogamic mates (Miller et al. 2010; Fig. 1A, right panel). Knockdown instead of clearance is performed because Wolbachia is a fixed obligate mutualist in $D$. paulistorum, providing vital but still undetermined functions for its native hosts (Miller et al. 2010). More recently, we could demonstrate selective neurotropism (the affinity to nervous tissue) of native D. paulistorum Wolbachia to defined female and male brain regions, known as functionally important for mating behavior and memory (Strunov et al. 2017). In addition to governing assortative mating behavior of $D$. paulistorum females, we speculate that perturbations of the Wolbachia-Drosophila homeostasis in males might induce assortative mating behavior between per se compatible, homogamic mates, at least under experimental conditions (Fig. 1B). Finally we speculate that under certain conditions like obligate mutualism and tropism of the endosymbiont to host organs associated with sexual behavior, Wolbachia can act as an influential and dynamic factor for modulating sexual behavior, which, because of their sensitivity to exogenous factors such as stress and antibiotics (Reynolds and Hoffmann 2002; Mouton et al. 2006; Weeks et al. 2007), plus their high innate mutability (Chrostek et al. 2013; Schneider et al. 2013; Newton and Sheehan 2014), can possibly initiate the process of sexual isolation, at least under experimental laboratory conditions. Their potential impact on speciation in nature, however, remains elusive.

The key components of premating sexual isolation mechanisms are visual, acoustic, and chemical courtship signals. In many insects, sexual pheromones play an important role as olfactory signals influencing mate choice (Blomquist and Bagnères 2010; Chung and Carroll 2015; Dembeck et al. 2015). In $D$. paulistorum, males from the six semispecies exhibit characteristic sexual pheromone profiles (same compounds but different quantities), including four male-specific long-chained ester compounds, which are recognized by females (Kim et al. 2004; Chao et al. 2010). In contrast to other Drosophila species such as D. melanogaster, no female-specific compounds are present in this system. Hence, the authors of previous studies (Kim et al. 2004; Chao et al. 2010) concluded that, based on chemical profiles, D. paulistorum females accept homogamic (compatible), but reject heterogamic (incompatible) males as mates (Chao et al. 2010). Forced mating between heterogamic mates carrying incompatible Wolbachia strains is highly detrimental for both host and symbionts by triggering high levels of embryonic lethality and complete male sterility among $\mathrm{F}_{1}$ hybrids (Ehrman 1968; Kernaghan and 
a Mate choice in D. paulistorum: Wolbachia-knockdown females lose assortative mating behavior against heterogamic wild type males (Miller et al. 2010)

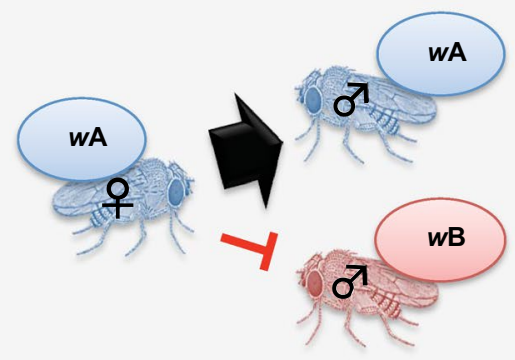

wild type

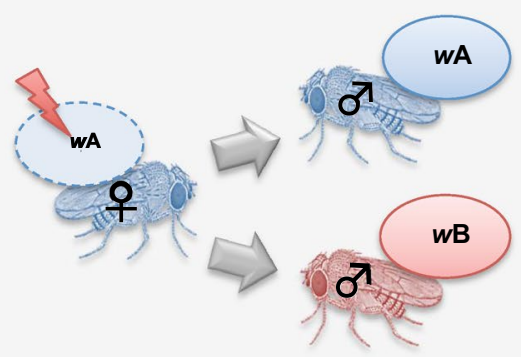

Wolbachia knockdown (red flash)

b Mate choice in D. paulistorum: Wolbachia-knockdown males are rejected by homogamic wild type females (this study)
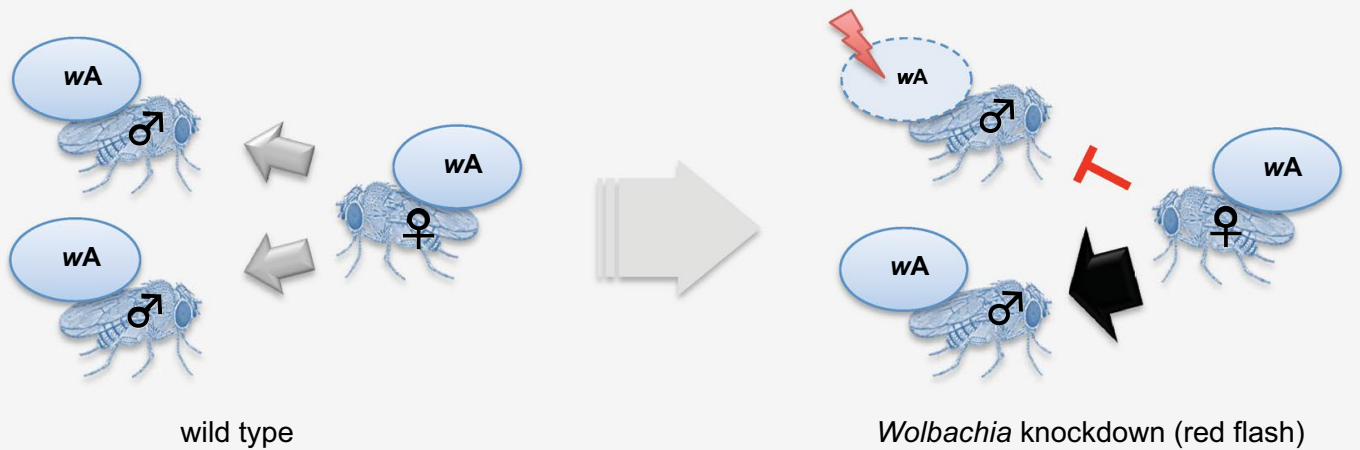

Wolbachia knockdown (red flash)

Fig. 1 Impact of Wolbachia on mate choice in D. paulistorum. a Mate choice in D. paulistorum: Wolbachia-knockdown females lose assortative mating behavior against heterogamic wild type males. Left: wild type females (blue) infected with Wolbachia A $(w \mathrm{~A})$ express strong assortative mating behavior (red block) against males of a different semispecies (red) carrying a different, incompatible Wolbachia (wB). Right: Wolbachia kd females (symbolized with red flash) with reduced titers of $w$ A lose assortative mating behavior (grey arrows) and hence mate randomly with males from same (blue) but also from different/incompatible (red) semispecies. Female knockdown phenotype: loss of assortative mating behavior. Data

Ehrman 1970; Miller et al. 2010). Hence strong selection should act on both intimate partners to evolve or maintain such mechanisms for mate recognition.

Here we experimentally investigated whether bacterial symbionts are capable of initiating artificial de novo reproductive isolation (RI) by targeting host-derived olfactory cues. Therefore, we have (i) transiently knocked down obligate Wolbachia in $D$. paulistorum males, (ii) assayed their mating success in homogamic choice assays with wild type females, (iii) monitored their sexual pheromone profiles, and (iv) investigated the presence of Wolbachia in putative pheromone-producing cells. taken from (Miller et al. 2010). b Mate choice in D. paulistorum: Wolbachia-knockdown males are rejected by homogamic wildtype females. Left: wild type males are accepted randomly (grey arrows) for mating by females of the same semispecies (all blue), carrying the same/compatible Wolbachia (both wA). Right: Wolbachia kd males (indicated by red flash) with reduced titers of $w \mathrm{~A}$ are rejected as mate partners (red block) from wild type females of the same semispecies. Thickness of arrows indicates strength of mate choice between partners: thick black arrow $=$ high mate preference, red block = assortative mating, and grey medium arrow = lack of mate choice, i.e., random mating. $k d$ knockdown. (Color figure online)

\section{Methods}

\section{Fly strains and generation of Wolbachia-knockdown (kd), axenic (et), and penicillin/streptomycin-treated (ps) flies}

Reference strains for two semispecies from the Drosophila paulistorum superspecies were chosen for this study (Amazonian, A28 and Orinocan, O11; originally described in Burla et al. 1949; Dobzhansky and Pavlovsky 1966). The Wolbachia infection status (wPau) of these D. paulistorum strains was previously described in Miller et al. 
2010. In brief, A28 carries very low densities of the Wolbachia wPauAM strain, and O11 is infected with the high-titer $w$ PauOR strain (Miller et al. 2010). Wolbachia positive controls for Polymerase chain reaction (PCR) assays were $D$. willistoni P98 and JS6.3, both lab strains carrying native high-titer Wolbachia ( $w$ Wil; Miller and Riegler 2006). The D. melanogaster $\mathrm{H} 2$-strain ( $w \mathrm{Mel}$; Miller and Riegler 2006) was used as an additional Wolbachia positive control. Wolbachia negative controls for PCR were D. simulans NouméaTC (Poinsot et al. 2000), D. melanogaster $\mathrm{w}^{1118}$ (BDSC, USA), and D. willistoni Willi3 (14030-0811.2 DSSC, USA). Flies were reared on Formula 4-24 Drosophila instant food (Carolina, USA) at $24-25{ }^{\circ} \mathrm{C}$ on a $12 \mathrm{~h}$ light-dark cycle.

Wolbachia-knockdown lines A2 $8^{\mathrm{kd}}$ and $\mathrm{O} 11^{\mathrm{kd}}$ were generated by mass-treating wild type flies with $0.2 \%$ (w/v) rifampicin (Duchefa, Netherlands) added to Formula 4-24 Drosophila instant food (Carolina, USA) over three sequential generations $\left(\mathrm{T}_{1}-\mathrm{T}_{3}\right)$. The low dosage of the antibiotic is sublethal and allows for reduction of mutualistic Wolbachia in D. paulistorum (Miller et al. 2010). Offspring from $T_{3}$ parents were then transferred onto antibiotic-free food for more than 10 generations under a mass-rearing regime designated as knockdown pools (A28 ${ }^{\mathrm{kd}}$, O11 ${ }^{\mathrm{kd}}$; Supporting Information Fig. S1). In parallel, $\mathrm{F}_{2}{ }^{\mathrm{kd}}$ was used to initiate $8-10$ isofemale lines per semispecies (A28 ${ }^{\mathrm{kd}-\mathrm{i}}, \mathrm{O} 11^{\mathrm{kd}-\mathrm{i}}$; Supporting Information Fig. S1). Biological assays were performed at different generations between $\mathrm{F}_{4}{ }^{\mathrm{kd}}$ and $\mathrm{F}_{13}{ }^{\mathrm{kd}}$ and their respective Wolbachia load was monitored by qPCR (see below). Gut flora restoration (gfr) lines were generated by feeding the native gut microbiome to knockdown flies as follows: $\mathrm{A} 28^{\mathrm{wt}}$ and $\mathrm{O} 11^{\mathrm{wt}}$ virgin females were kept on instant food for 2-3 days to collect feces. Flies were then removed and the corresponding knockdown $(\mathrm{kd})$ flies were transferred onto the feces-containing food vials. After egg deposition adults were removed and emerging flies were consequently used as gfr lines. Axenic ('gut microbe-free flies') were generated by consequently washing freshly collected eggs from A28 ${ }^{\mathrm{wt}}$ and $\mathrm{O} 11^{\mathrm{wt}}$ with $70 \%$ ethanol for $5 \mathrm{~min}$ to surface-sterilize them. This treatment prevented larvae ingesting microbes from the outer layer of the eggshell when hatching. Collected eggs were then transferred into food vials and hatching $\mathrm{F}_{1}$ and $\mathrm{F}_{2}$ adults $\left(\mathrm{A} 28^{\mathrm{et}}, \mathrm{O} 11^{\mathrm{et}}\right)$ were consequently used for mate choice assays. Penicillin/ streptomycin-treated (ps) flies were generated by supplementing Formula 4-24 Drosophila instant food (Carolina, USA) with a 1:100 dilution of a $100 \times$ pen/strep stock solution $(10,000 \mathrm{units} / \mathrm{ml}$ penicillin, $10,000 \mu \mathrm{g} / \mathrm{ml}$ streptomycin). $\mathrm{A} 28^{\mathrm{wt}}$ and $\mathrm{O} 11^{\mathrm{wt}}$ were kept on this food for at least 1 week to lay eggs and the hatching $\mathrm{F}_{1}\left(\mathrm{~A} 28^{\mathrm{ps}}, \mathrm{O} 11^{\mathrm{ps}}\right)$ was consequently used for mate choice assays against the wt counterparts. Strains are reported in Table S1.

\section{Quantification of wPau Wolbachia}

DNA was extracted from a pool of ten 3-day old flies using Gentra Puregene chemistry (Qiagen, Germany). Concentrations of DNA were measured on a Nanodrop 2000 spectrophotometer. Consequently, diagnostic Wolbachia-PCR (quantitative real time PCR) was performed using the Wolbachia outer surface protein gene $w s p$ (Yamada et al. 2007), and the Wolbachia-specific $16 \mathrm{~S}$ rRNA gene (16SW_RTf 5'-CCTGATCCAGCCATGCCGCAT-3', 5'-16SW_RTr CGGCTGCTGGCACGGAGTTA-3'). The $w s p$ primer set generates a $69 \mathrm{bp}$ amplicon, and the $16 \mathrm{~S}$ rRNA set produces a 77 bp fragment. Wolbachia titers obtained with MxPro QPCR v4.10 Software (Agilent Technologies, USA) were normalized against Drosophila ribosomal protein RPS17 (RPSmel_f 5'-CACTCCCAGGTGCGTGGTAT-3', RPSwil_r 5'-GGAAACGGCGGGCACGTA-3'). A temperature profile of $95{ }^{\circ} \mathrm{C}$ for $3 \mathrm{~s}, 60^{\circ} \mathrm{C}$ for $20 \mathrm{~s}$, and $72{ }^{\circ} \mathrm{C}$ for $6 \mathrm{~s}$ was used for 45 cycles. All samples were run in duplicates on a Stratagene MxPro4000 cycler. Quantitative PCR with $w s p$ was run to confirm results obtained with the $16 \mathrm{~S}$ rRNA primer set. Only results for the latter one are presented in the manuscript.

\section{Measuring sexual isolation via multiple mate choice assays}

Mate choice assays between wild type, knockdown and control assays involved double blind direct multiple-mating observations carried out mornings at room temperature in daylight. Virgin flies were aged 2-3 days (females isolated from males), and half were marked via distal wing clips before running the choice assay. These marks were rotated (wing to wing and knockdown to wild type). Such minute abrasions have tested neutral regarding behavioral influences in this superspecies (Dobzhansky and Pavlovsky 1966; Leonard and Ehrman 1983). For each mate choice assay five replicas and 120 mating events (240 individual flies) were

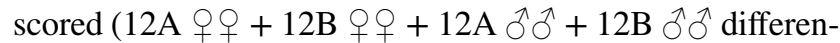
tiated by alternating wing clips; Supporting information Fig. S2a, b). Flies were placed (females first) in mating observation chambers $(10 \mathrm{~cm}$ in diameter) without anesthetization and the following parameters were scored until all flies copulated in approximately 30-40 min: the time each mating took place (from start of observations; each copulation approximately lasted $15-17 \mathrm{~min}$ ); its sequence among other copulae which occured; where in the chamber the mating pair was located; the kind of female involved; and the kind of male involved. Recording the location of each copula, even upside down, prevented scoring a copula more than once. Sexual isolation index (SII) was computed according to the following formula (Malogolowkin-Cohen et al. 1965). 
$\mathrm{SII}=($ nho-nhe $) / \mathrm{N}$, where $n$ ho is the number of homogamic matings, nhe is the number of heterogamic matings, and $N$ the total number of matings. SIIs range from -1.00 (preference for unlikes, heterogamy) through 0 (random mating) to +1.00 (preference for likes, homogamy). This experimental design is not devoid of bias. Indeed, when the number of partners is finite and remating is limited, the choice of the last individuals is conditioned by the choice of the previous ones. This could lead to erroneous signals for assortative mating, e.g. when both males and females from the same population tend to mate earlier than those from the other population (Ehrman and Parsons 1981). However, unbiased rates of assortative mating could be estimated by accounting for the order of mating pairs, using a statistical model described extensively in Supporting Methods. This method provides the maximum-likelihood estimates of the assortative mating coefficient (called eSII, or $h$ in the model and Supporting Methods) and accounts for the possibility of remating in males. Several remating rates were tested and did not significantly influence the estimation of SII (see Fig. S3), hence in practice a remating rate of 0.5 was chosen for the general analysis (Tables S2-S4). To avoid convergence issues, the female remating rate was set to 0.001 . Two additional parameters (biases in mating order for males and females) were also estimated by the model (Table S5). However, their biological interpretation is not that straightforward as they may correspond to either a general preference for one population of one sex, or a different mating speed between both populations. The statistical departure of the SII from 0 was estimated by a likelihood ratio test. Simulations showed that this procedure efficiently corrects for such mating order biases, and was even slightly more powerful than homogeneity (Fisher) tests when mating order was unbiased.

The model was implemented in $\mathrm{R}$ version 3.1.1 ( $\mathrm{R}$ Core Team 2016), the code is available in Supporting Methods, along with the raw data. A comparison of the uncorrected SII and the model-estimated SII is provided in Supporting Information Fig. S3 and Tables S2-S4. Hereafter, we will refer only to the estimated SII that will be simply called eSII.

\section{Analysis of cuticular hydrocarbons (CHCs) via gas chromatography-ion trap mass spectrometry (GC- MS)}

Male virgin flies were collected, isolated from females, and aged to 3 days. Flies were pooled in glass vials and submerged in $1 \mathrm{ml}$ of HPLC-grade hexane (Carl Roth, Germany). Replicates consisted of 10 males per sample. We did nine replicates for $\mathrm{A} 28^{\mathrm{wt}}$ and 10 replicates for each $\mathrm{A} 28^{\mathrm{kd}}$, $\mathrm{O} 11^{\mathrm{wt}}$ and $\mathrm{O} 11^{\mathrm{kd}}$. Two $\mu \mathrm{g}$ of octadecane (C18) per sample was added as the internal standard for absolute quantification of CHCs. Extraction of CHCs was performed for $10 \mathrm{~min}$ at room temperature under constant agitation, after which the flies were removed. Extracts were evaporated to about 20-30 $\mu \mathrm{l}$ of hexane under a constant stream of argon, and

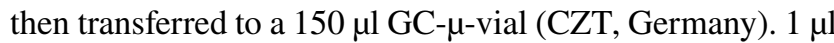
aliquots were injected into a Varian 450GC gas chromatograph coupled to a Varian 240MS mass spectrometer (Agilent Technologies, Germany). A DB5-MS capillary column (30 $\mathrm{m} \times 0.25 \mathrm{~mm}$ diameter, film thickness: $0.25 \mu \mathrm{m}$, Agilent Technologies, Germany) was used and the GC was programmed from $150{ }^{\circ} \mathrm{C}$ to $300{ }^{\circ} \mathrm{C}$ at $15^{\circ} \mathrm{C} / \mathrm{min}$ with a $27 \mathrm{~min}$ final isothermal hold. Helium, with a constant flow rate of $1 \mathrm{ml} / \mathrm{min}$, was used as carrier gas. Recording of mass spectra was performed using electron ionization (EI-MS) in external ionization mode and data acquisition plus quantifications were done with MS Workstation v6.9.3 Software (Agilent Technologies, Germany). Consequently, peaks were identified by their mass spectra in comparison to previously published hydrocarbon profile analyses of D. paulistorum (Kim et al. 2004; Chao et al. 2010) and D. melanogaster (Ueyama et al. 2005). Hydrocarbon quantities were calculated from peak areas and then centered log-ratio-transformed according to Aitchinson 1986. To test for differences in chemical profiles between wild type and knockdown individuals, principal component analyses (PCAs) based on eigenanalysis of covariances were performed to reduce numbers of variables. Consequently, resulting PCs were used for discriminant analyses (DAs), to test for among-group differences.

\section{Fluorescence in situ hybridization (FISH) on D. paulistorum oenocytes}

Ten to 15 female and male abdomen per semispecies were dissected in RNase-free $1 \times$ phosphate buffered saline (PBS). After removing inner organs, cuticles were fixed in $3.7 \%$ formaldehyde in RNase-free PBS for $20 \mathrm{~min}$ at room temperature and consequently washed with PBTX $(1 \times$ PBS, $0.3 \%$ Triton-X 100). After permeabilization with $70 \%$ ethanol overnight at $4{ }^{\circ} \mathrm{C}$, samples were hybridized overnight in $10 \%$ formamide, saline sodium citrate (SSC) and $0.5 \mathrm{nmol}$ of CAL Fluor Red 590-labeled customized Wolbachia 16-23S rRNA probe (Biosearch Technologies, USA; Schneider et al., in press). Samples were then washed in $10 \%$ formamide and SSC, stained with DAPI-SSC $(1 \mu \mathrm{g} / \mathrm{ml})$ and mounted in Roti ${ }^{\circledR}-M o u n t$ FluorCare (Carl Roth, Germany) on sterilized microscope slides. Cuticles were analyzed on an Olympus FluoView confocal microscope. Beam paths were adjusted to excitation/emission peaks of used fluorophores: $569 / 591 \mathrm{~nm}$ for CAL Fluor Red 590 (Wolbachia), and 350/450 nm for 4',6-diamidin-2-phenylindol (DAPI). Images were processed with Fiji software (http://fiji.sc). Hybridization experiment was repeated twice and a minimum of 15 flies was assayed in each experiment. 


\section{Results}

\section{Knockdown of obligate Wolbachia in Drosophila paulistorum semispecies is of transient nature}

To test whether manipulation of native Wolbachia titers and associated disruption of the host-symbiont homeostasis can trigger de novo reproductive isolation (RI) in D. paulistorum, we generated Wolbachia-knockdown (kd) males of two different semispecies (Amazonian: A28, and Orinocan: O11) by mild rifampicin treatment for three consecutive generations (T1-T3) and in the following generations on regular media without antibiotics $\left(\mathrm{F}_{1}{ }^{\mathrm{kd}}-\mathrm{F}_{14}{ }^{\mathrm{kd}}\right)$ for restoration. For details see Supporting Information Table S1, Fig. S1. Global Wolbachia titers of these males $\left(\mathrm{A} 28^{\mathrm{kd}}, \mathrm{O} 11^{\mathrm{kd}}\right)$ were tested against wild type (wt) controls (A28 ${ }^{\mathrm{wt}}, \mathrm{O} 11^{\mathrm{wt}}$ ) in quantitative real time PCR (qPCR) assays targeting the Wolbachia $16 S$ ribosomal RNA gene. Assays obtained from $\mathrm{F}_{7}{ }^{\mathrm{kd}}$ (knockdown generation 7) revealed massive titer reduction to about 5 and $14 \%$ of the average native wt Wolbachia titers (Fig. 2a, b).

To further assess whether Wolbachia titers return to native levels in later generations post kd, we tested symbiont load by $\mathrm{F}_{14}$ and earlier generations. Whereas in $\mathrm{O} 11$

a

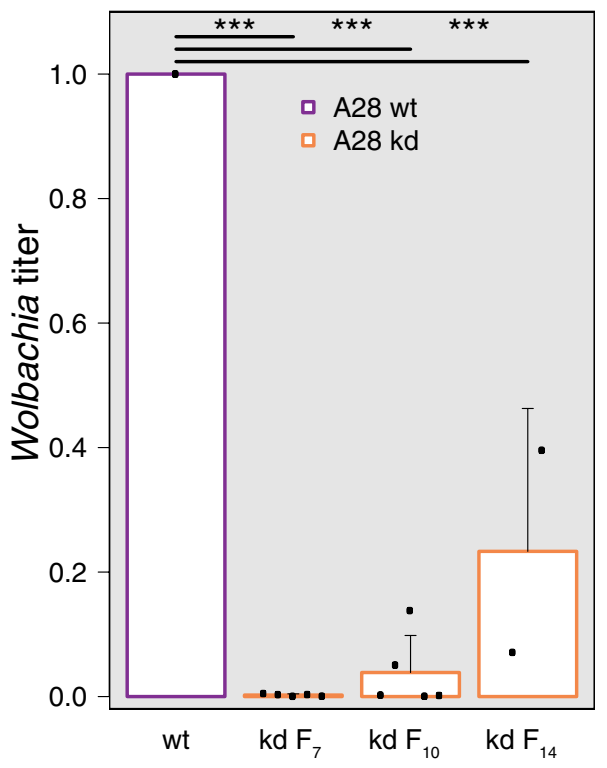

Fig. 2 Quantitative analysis of Wolbachia titers in wild type (wt) and knockdown (kd) D. paulistorum males. Bars represent Wolbachia titers measured via quantitative real time PCR on DNA from whole body extracts of A28 (a), and O11 (b) using Wolbachia 16S rRNA normalized against Drosophila ribosomal protein 17 (RPS17). Each purple bar represents the mean Wolbachia titer in wt males (mean from 8 to 10 biological replicates is plotted). Orange bars represent titers in $\mathrm{F}_{7} / \mathrm{F}_{14} \mathrm{kd}$ males (post treatment); individual biological repli- the global symbiont titer was close to wt-levels at $\mathrm{F}_{14}$ (90\%; Fig. 2b), A28 flies have gradually reached only $23 \%$ of their wt-titer at this time point (Fig. 2a).

\section{Mate choice assays reveal de novo assortative mating phenotype of wild type (wt) females towards Wolbachia-knockdown males}

Among sympatric $D$. paulistorum semispecies, no hybrids are formed inter-semispecifically in nature (Dobzhansky and Spassky 1959). When performing inter-semispecific mate choice assays involving $\mathrm{A} 28^{\mathrm{wt}}$ and $\mathrm{O} 11^{\mathrm{wt}}$ semispecies, we observed strong RI, revealed by a high estimated Sexual Isolation Index (eSII) (Ehrman 1965; Ehrman and Powell 1982; Supporting Information: Table S2, assays 1, 2). In contrast, intra-semispecific control assays showed no assortative mating in standard interbreeding 'pool' lines (Fig. 3a, b wt $\times w t$ (purple) and Supporting Information Table S2, assays 3, 4). Results of statistical testing are summarized in Table S2.

In order to test our hypothesis that manipulation of the native Wolbachia titer and the associated disruption of the host-symbiont homeostasis in D. paulistorum might trigger de novo premating isolation intra-semispecifically, we assayed mating behavior of Wolbachia-kd pool lines towards wt flies of the same semispecies (Fig. 3a, b, orange, and Table S3,

b

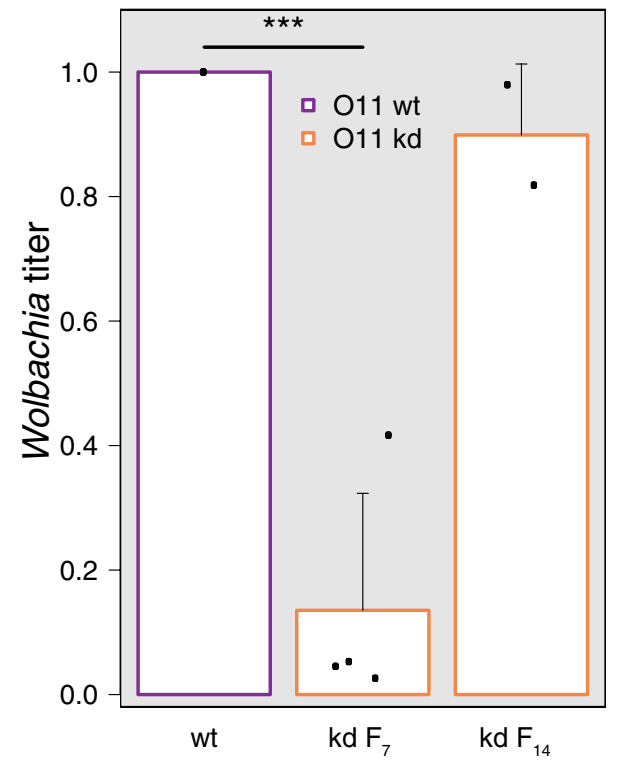

cates are shown as black dots. In addition, for $\mathrm{A} 28^{\mathrm{kd}}, \mathrm{F}_{10}$ titers were tested. Kd-titers are relative to wt ones (set to 1). Each sample was run in technical duplicates. Error bars represent the standard deviation of the biological replicates. Asterisks indicate significance of differences between titer levels. $P$ values were calculated using Fisher's exact test. $w t$ wild type, $F_{7}, F_{10}, F_{14}$ fly generations 7,10 and 14 . (Color figure online) 
assays 1-6). Assays run with knockdown flies at generation $\mathrm{F}_{4}$ or $\mathrm{F}_{5}$ post-treatment, consistently showed high eSII, i.e. mating between likes rather than unlikes. This points towards de novo mate discrimination between wt and kd flies from the same semispecies that significantly differ in their symbiont load ( $\mathrm{kd} \mathrm{F}_{7}$ in Fig. 2a, b). However, at generation $\mathrm{F}_{13}$ homogamy was less pronounced among all of them, and eSII did not differ significantly from what is expected under random mating. Importantly, although $\mathrm{O} 11$ flies showed rapid increase of Wolbachia levels by $\mathrm{kd} \mathrm{F}_{14}$ (Fig. 2b), only a slower, gradual titer increase was observed in A28 (Fig. 2a). Hence the restoration of the random mating phenotype in $\mathrm{O} 11$ might directly correlate with the global restoration of the symbiont level at faster pace, whereas the reversion to random mating of A28 flies might depend on a critical titer threshold of Wolbachia and/or their tropism to sensitive host tissues such as oenocytes (see discussion).

To rule out that drift effects were responsible for observed de novo sexual isolation, we additionally assayed $\mathrm{wt}$ and $\mathrm{kd}$ lines that were reared as ten isofemale lines per semispecies $\left(\mathrm{A} 28^{\mathrm{wt}-\mathrm{i}}, \mathrm{O} 11^{\mathrm{wt}-\mathrm{i}}\right.$ and $\mathrm{A} 28^{\mathrm{kd}-\mathrm{i}}, \mathrm{O} 11^{\mathrm{kd}-\mathrm{i}}$, respectively). First, two out of ten randomly picked control isofemale lines (wt-i) representing each semispecies were tested against each other (intra) in $\mathrm{F}_{10}$ in order to verify random mating between them (Fig. 3c, $\mathrm{d}$ wt-i $\times w t-i$, purple, and Supporting Information Table S2, assays 5-8). The observed low eSIIs indicated the absence of any drift-dependent sexual isolation. To test for emerging sexual isolation between kd-isofemale lines upon drift (as a response to Wolbachia-kd and consequent restoration) we performed intra-semispecific choice assays using independent $\mathrm{F}_{8}$ isofemale knockdown lines (kd-i). Surprisingly in this case the assays revealed significant isolation between them ( $p$ values $<10^{-4}$; Fig. 3c, d, pink, and Supporting Information Table S3, assays 7,8 ).

Taken together, control assays between independent wt isofemale lines rule out drift as a potential factor for triggering de novo premating sexual isolation observed between wt and kd lines, whereas independent knockdown lines have possibly drifted apart from each other upon isolation having potentially different levels and/or individual tissue tropisms of Wolbachia during restoration at $\mathrm{F}_{8}$. Overall, the emergence of high eSIIs in intrastrain assays suggests that even slight perturbations of the native Wolbachia - D. paulistorum homeostasis and/or tropism are sufficient to induce de novo RI in this system, even between individual knockdown isofemale lines. This latter and quite intriguing observation, however, will need further investigations, which are beyond the scope of our current analyses (see discussion).

\section{No evidence for influence of gut microbiota on de novo assortative mating phenotype}

Earlier and recent studies, however, have addressed the potential influence of diet and consequently the gut microbiome on host sexual isolation not only in $D$. pseudoobscura (Dodd et al. 1989), but also in highly inbred lines of $D$. melanogaster (Sharon et al. 2010; Ringo et al. 2011). Here, sexual isolation can be triggered by manipulating the fly's gut microbiome, based on a certain dietary regime. However, two recent studies have questioned the general role for gut bacteria or diet composition in driving reproductive isolation in D. melanogaster (Najarro et al. 2015; Leftwich et al. 2017). In the light of these still controversial findings obtained from inbred $D$. melanogaster strains, we have tested D. paulistorum gut flora restored (gfr) lines, where $\mathrm{kd}$ lines were fed with wt feces, in parallel with our unfed kd lines (see "Methods" for details). Assays with these lines and wt flies revealed almost complete SII suggesting that gut flora restoration does not affect the de novo assortative mating phenotype ( $p$ values $<10^{-4}$, Fig. 3e, and Supporting Information Table $\mathrm{S} 4$, assays 1, 2). To further exclude an effect of the gut microbiome associated with the egg smear, we assayed axenic flies, i.e., eggs washed with ethanol (et, Fig. 3f, and Supporting Information Table S4, assays 3, 4), and penicillin/streptomycin-treated flies (ps, Fig. 3g, purple, and Supporting Information Table S4, assays 5, 6). Mating behavior with both sets were compatible with random mating (absence of assortative mating). Hence, in contrast to rifampicin, which acts on Wolbachia levels, neither sterilizing eggs, nor treatments with penicillin/streptomycin had any effect on mate choice behavior in this system. Furthermore, to test whether penicillin/streptomycin affects mate behavior of females we performed inter-semispecific control assay between wildtype A28 and penicillin/streptomycintreated $\mathrm{O} 11$ flies that still revealed high sexual isolation (ps, Fig. 3g, yellow, Supporting Information Table S4, assay 7, $p$ value $<10^{-4}$ ), confirming that penicillin/streptomycinsensitive gut microbes in females have no effect on mating behavior in this system.

Importantly, we are aware that none of our control assays on its own can exclude the spurious presence of some hidden non-Wolbachia microbe affecting mate behavior. However, the combination of three independent control assays, i.e., gut-flora restoration, egg-surface sterilization and penicillin/streptomycin-treatment, strongly supports our hypothesis that endosymbiotic Wolbachia, which are resilient to penicillin/streptomycin and egg surface sterilizing treatments (Audsley et al. 2017; Leclerq et al. 2017; Ye et al. 2017), are interfering with mate discrimination of $D$. paulistorum in both sexes and not any other bacteria.

Concordantly, only rifampicin treatment massively reduces Wolbachia load and induces de novo assortative 

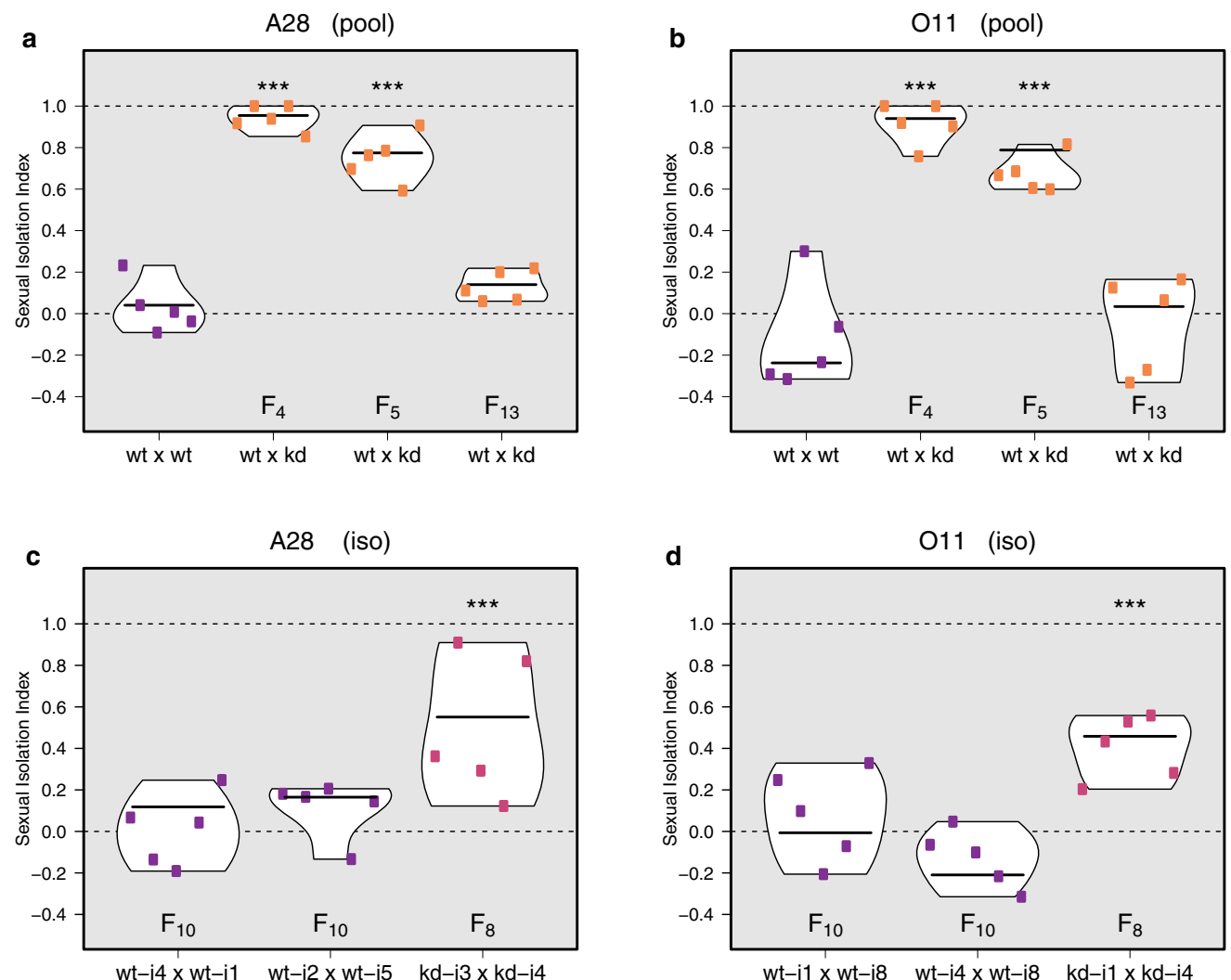

$0: 1$
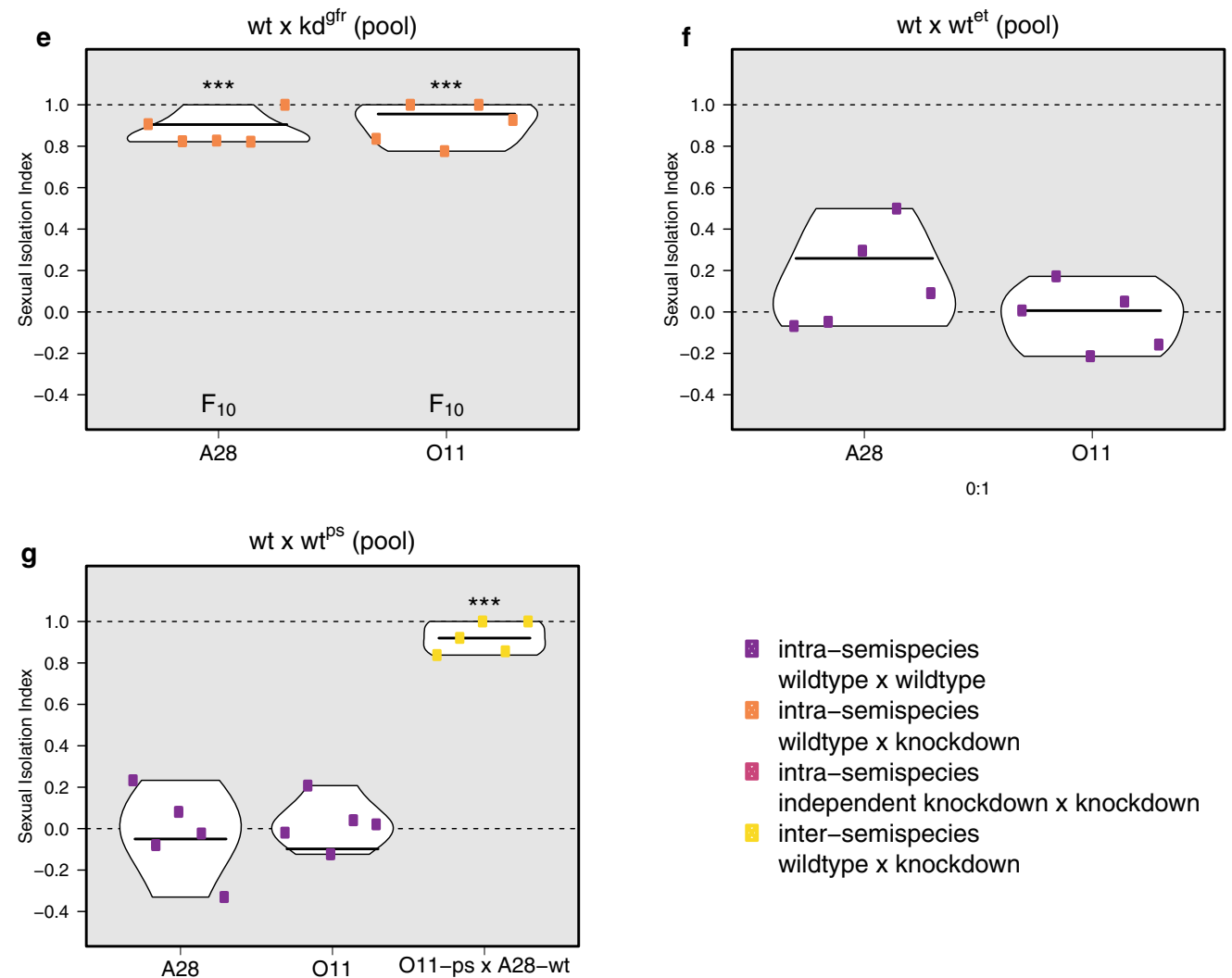

intra-semispecies wildtype $\mathrm{x}$ wildtype

intra-semispecies wildtype $\mathrm{x}$ knockdown

intra-semispecies independent knockdown x knockdown inter-semispecies wildtype $\mathrm{x}$ knockdown 
4Fig. 3 Violin plots showing estimated sexual Isolation Index (eSII) in multiple choice assays between $D$. paulistorum wild type (wt), Wolbachia-knockdown (kd), axenic (et), and penicillin/streptomycintreated (ps) flies. (a, b) Intra-semispecific mate choice assays with pool lines. Wild type (wt) flies (control, in purple) or knockdown (kd) flies (in orange) were assayed at generations $\mathrm{F}_{4}, \mathrm{~F}_{5}, \mathrm{~F}_{13}$, against wt flies, for A28 and O11. (c, d) Intra-semispecific mate choice assays with isofemale lines. wt vs. wt (purple), and kd vs. kd (pink) mating choice assays were performed between different isofemale lines, respectively at generation $\mathrm{F}_{10}$ and $\mathrm{F}_{8}$. e Intra-semispecific assays between wt and gut-flora-restored flies (gfr) performed at generation $\mathrm{F}_{10}$ for A28 and O11. $\mathbf{f}$ Intra-semispecific assays between wt and ethanol-washed wt flies (et) performed at generation $\mathrm{F}_{2}$ for A28 and O11. g Intra-semispecific assays between wt and penicillin/streptomycin-treated flies (ps), performed at generation $\mathrm{F}_{3}$ for the A28 and O11. The last assay (yellow) is an additional inter-semispecific assay between wt and ps flies. For all assays, the model-estimated SII was used on either individual replicates (dots), or considering the 5 replicates (horizontal bars). Asterisks denote assays for which the likelihood ratio test (LRT) is highly significant $\left(p\right.$ values $\left.<10^{-4}\right)$, the null model being random mating $(\mathrm{SII}=0)$. All the $p$ values are reported in Tables S2-S4. (Color figure online)

mating behavior of wildtype females against knockdown males from the same semispecies (this study) that also selectively triggers loss of assortative mating behavior in knockdown females against males from a different semispecies (Fig. 3g, yellow; Miller et al. 2010).

\section{Sexual pheromone profiles are altered in $D$. paulistorum knockdown males}

Based on the observed de novo assortative mating phenotype, we tested whether the pheromone composition of Wolbachia-kd males was altered in comparison with wt males. Males from all six D. paulistorum semispecies exhibit characteristic pheromone profiles (all share the same 15 major compounds but in varying quantities), including four malespecific long-chain esters, which are recognized by females as a semispecific blend because of the differences in their relative concentrations (Supporting Information Fig. S4; Kim et al. 2004; Chao et al. 2010). In contrast to other Drosophila species such as D. melanogaster, no female-specific compounds are known in D. paulistorum (Chao et al. 2010) and mate decisions appear-to our current knowledge-to be exclusively made by females (Ehrman 1965; Ehrman and Parsons 1981). Here we extended hydrocarbon profile analyses to a total of 27 compounds found in all tested semispecies by adding two new, unknown compounds (Supporting Information Table S6, compounds 9, 13) and by resolving the original $\mathrm{C} 33, \mathrm{C} 35$, and $\mathrm{C} 37$ peak clusters $(\mathrm{C}=$ chain length of the compound; 33, 35, and 37 carbon atoms).

In full agreement with earlier reports (Kim et al. 2004; Chao et al. 2010), discriminant analyses of sex pheromone profiles from $\mathrm{A} 28^{\mathrm{wt}}$ and $\mathrm{O} 11^{\mathrm{wt}}$ males revealed major differences among the semispecies (Supporting Information Fig. S5). In order to test for differences in male pheromone profiles upon Wolbachia-kd, we compared profiles between $\mathrm{F}_{7} \mathrm{kd}$ males and wt males for each semispecies. Based on the 27 quantified components (Supporting Information Table S6), six principal components were extracted capturing $84.9 \%$ of the total variance. The discriminant analysis revealed statistically significant differences between both semi-species A28 ${ }^{\mathrm{wt}}$ and $\mathrm{O} 11^{\mathrm{wt}}$ males (Wilks' Lambda $\left.=0.178, \mathrm{X}^{2}=24.2, \mathrm{df}=6, p<0.001\right)$ as well as between $\mathrm{A} 28^{\mathrm{wt}}$ and $\mathrm{A} 28^{\mathrm{kd}}$ males (Wilks' Lambda $=0.059$, $\left.\mathrm{X}^{2}=39.6, \mathrm{df}=6, p<0.001\right)$ and also between $\mathrm{O} 11^{\mathrm{wt}}$ and O11 ${ }^{\mathrm{kd}}$ (Wilks' 446 Lambda $=0.117, \mathrm{X}^{2}=34.3, \mathrm{df}=6$, $p<0.001$, Supporting Information Fig. S5).To further analyze differences in pheromone profiles between wt and $\mathrm{kd}$ males, we calculated the relative quantities of the four malespecific compounds in D. paulistorum male profiles (11-docosenyl-acetate, DA, 19-triacontenyl-acetate, TA, di-unsaturated acetate $\mathrm{C}_{32} \mathrm{H}_{60} \mathrm{O}_{2}$, DU, and methyl-(Z)-tetradecanoate, $\mathrm{MD})$. As shown in Fig. 4, we observed most drastic changes in quantities of these compounds in $\mathrm{A} 28^{\mathrm{kd}}$ males, where all four male-specific compounds were decreased between 9and 23-fold when compared to wt levels (Fig. 4a, $p<0.0001$ for all four compounds). Although not as drastic as A28 ${ }^{\mathrm{kd}}$, in $\mathrm{O} 11^{\mathrm{kd}}$ males at least one male-specific compound also showed significant changes: compared to $\mathrm{O} 11^{\mathrm{wt}}$ males, MD was reduced fivefold (Fig. 4b, $p=0.0399$ ).

\section{Wolbachia colonize oenocytes in D. paulistorum}

In insects, pheromone components are mainly synthesized in specialized cells located under the fly's cuticle, the oenocytes (reviewed in Blomquist and Bagnères 2010; Chung and Carroll 2015; Dembeck et al. 2015). We hypothesized that these specialized cells could serve a primary somatic target for Wolbachia to manipulate host pheromone profiles in D. paulistorum. Since male pheromone profiles were altered upon Wolbachia kd, we tested the infection status of male oenocytes in both $D$. paulistorum wt and kd individuals. As shown in Fig. 5, oenocytes from $\mathrm{O} 11^{\mathrm{wt}}$ females (Fig. 5a, a') and males (Fig. 5b, b') harbor Wolbachia. We could also detect the symbiont in oenocytes of A2 $8^{\text {wt }}$ males (not shown). Post Wolbachia-kd oenocytes, however, are cleared from the symbiont $\left(\mathrm{F}_{4} \mathrm{O} 11^{\mathrm{kd}}\right.$; males in Fig. $5 \mathrm{c}$; females in $c^{\prime}$ ). Since our mate choice assays indicated reversion to wt mating behavior, i.e., loss of de novo assortative mating, around $\mathrm{F}_{13 / 14}$ post Wolbachia-kd, we tested whether this phenotype correlates with a potential recolonization of Wolbachia to oenocytes around this generation post kd. As shown in Fig. 5d, oenocytes of $\mathrm{F}_{13} \mathrm{O} 11^{\mathrm{kd}}$ males are, at least partially, recolonized by the endosymbiont. Oenocytes of other Drosophila hosts like the wMel-infected D. melanogaster strain Harwich-2, (males in Fig. 5e, females in e') in which Wolbachia have evolved facultative symbiotic interactions and do not affect mate behavior, are devoid of the 

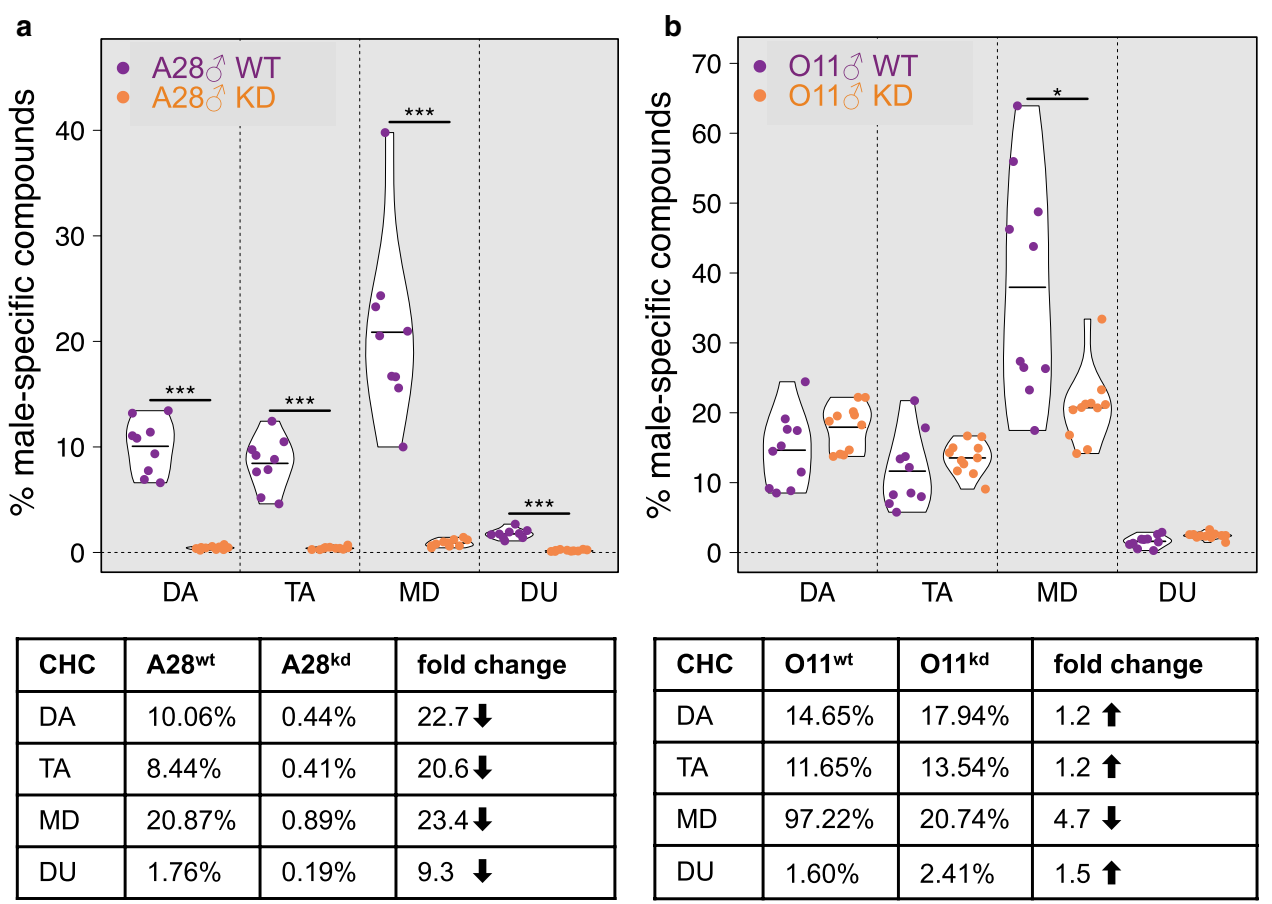

Fig. 4 Quantitative changes in D. paulistorum male-specific pheromone compounds upon Wolbachia-knockdown. Violin plots show percentage of the four male-specific ester compounds of the total pheromone profiles (27 compounds) of A28 (a) and O11 (b). Individual replicates for wild type controls (wt) are shown in purple, and in orange for $\mathrm{F}_{7}$ knockdown males (kd). Horizontal bars correspond to

symbiont. This is in contrast to $D$. paulistorum, where $w$ Pau Wolbachia are obligate mutualists affecting host behavior (Miller et al. 2010 and this study). Oenocytes derived from the Wolbachia-uninfected $D$. willistoni strain Willi3, a sister species of $D$. paulistorum, were used as negative controls (Fig. 5f). These data suggest that the oenocyte-tropism of $w$ Pau is a phenotypic specificity for the Wolbachia-D. paulistorum system.

\section{Discussion}

\section{Wolbachia-knockdown provokes a de novo assortative mating phenotype}

D. paulistorum semispecies are very sensitive to standard antibiotic treatments (Ehrman 1968; Kernaghan and Ehrman 1970) since in this symbiosis, Wolbachia is a fixed obligate mutualist providing vital, but still undetermined functions for its native hosts (Miller et al. 2010). Similar Wolbachiadependencies were found in the parasitoid wasp Asobara tabida (Dedeine et al. 2001; Pannebakker et al. 2007), bedbugs of the genus Cimex (Hosokawa et al. 2010; Nikoh et al.

the mean. Tables below violin plots list corresponding percent change of compounds plus $\mathrm{n}$-fold increase $(\uparrow)$ or decrease $(\downarrow)$ between wt and $\mathrm{kd}$. Asterisks indicate statistical significance based on two-tailed $p$ values from Student's $t$ tests. DA 11-docosenyl-acetate, TA 19-triacontenyl-acetate, $M D$ methyl-(Z)-tetradecanoate, $D U$ di-unsaturated acetate $\mathrm{C}_{32} \mathrm{H}_{60} \mathrm{O}_{2}$. (Color figure online)

2014; Moriyama et al. 2015), and in the rice water weevil Lissorhoptrus oryzophilus (Chen et al. 2012). Furthermore, even partial depletion of fixed mutualistic Wolbachia from filarial nematodes affects host fitness and fecundity but also triggers overexpression of host nuclear and mitochondrial genes in order to partially compensate the loss of some gene functions provided by Wolbachia (Pfarr et al. 2008; Strübing et al. 2010).

Here we have assayed for behavioral consequences of symbiont knockdowns in males of two different $D$. paulistorum semispecies, i.e., Wolbachia low-titer Amazonian (A28) and high titer Orinocan (O11) strains. Our data strongly suggest that in both systems partial knockdown of the endosymbiont in males significantly affects their attractiveness for homogamic wt-females, which seems to correlate with global titer levels. However, restoration to random mating in later generations post treatment (Fig. 3a, b) seems to correlate with the gradual quantitative reconstitution of global symbiont titers that are fast in O11 (Fig. 2b), but not in A28 (Fig. 2a). In our assays, A28 flies expressing random mating at $\mathrm{F}_{13}$ still show significantly lower global Wolbachia levels than wt flies. We speculate that reversion to random mating of A28 flies observed at later generations post-treatment might not depend on the global restoration of the symbiont 


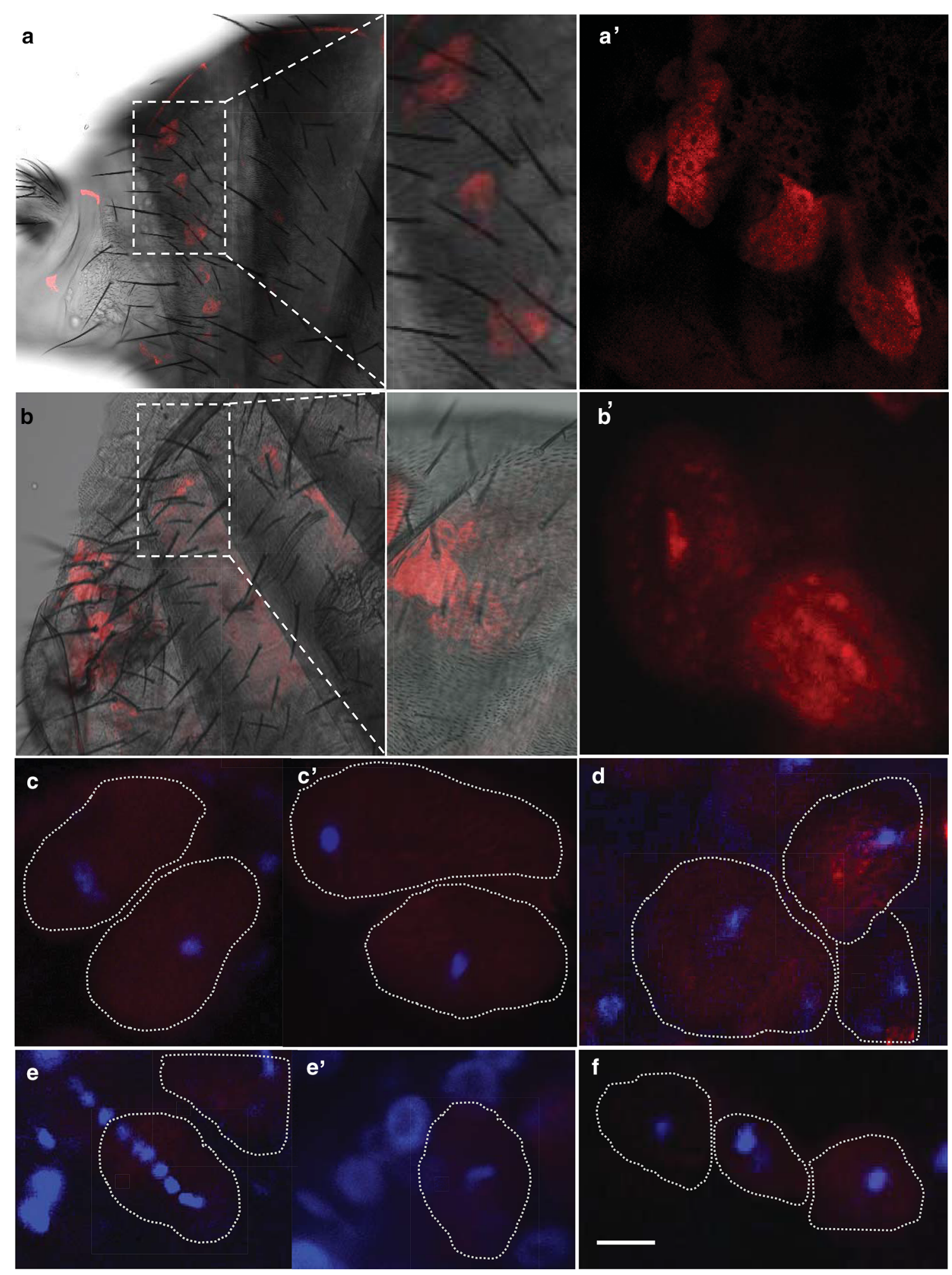

Fig. 5 Fluorescence in situ hybridization (FISH) on Drosophila oenocytes. (a, $\left.\mathbf{a}^{\prime}\right)$ Wolbachia are present in D. paulistorum $\mathrm{O} 11^{\mathrm{wt}}$ females, and $\left(\mathbf{b}, \mathbf{b}^{\prime}\right)$ in $\mathrm{O} 11^{\mathrm{wt}}$ males. c Symbionts are lacking from

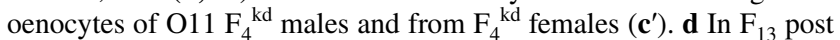
$\mathrm{kd}$, oenocytes seem recolonized by Wolbachia. $\left(\mathbf{e}, \mathbf{e}^{\prime}\right)$ Oenocytes from Wolbachia-infected D. melanogaster Harwich strain (H2) tested also negative. f Wolbachia-uninfected D. willistoni (Willi3) was used as negative control. Wolbachia are shown in red (16-23S rRNA-specific probe); Drosophila nuclei are stained in blue (DAPI). Grey dashed lines mark borders of oenocyte cells. Wol Wolbachia, kd knockdown. Scale bar is $10 \mu \mathrm{m}$. (Color figure online) 
titer in this semispecies to wt, but possibly because of a critical titer threshold and/or the symbiont's tropism to sensitive tissues and organs associated with mating behavior. In order to test this hypothesis, however, detailed temporal and spatial in situ quantifications of the symbiont in different host tissues during the restoration phase are required, which were beyond the scope of our current study.

As shown by this and earlier studies, under laboratory conditions different $D$. paulistorum semispecies express strong assortative mating behavior against each other, which is sensitive to rifampicin and tetracycline (Miller et al. 2010), but insensitive to penicillin and streptomycin that do not target the Wolbachia endosymbiont (this study). It seems feasible although not tested that strict female mate choice might prevent mating between incompatible members of different $D$. paulistorum semispecies also in nature. If true, this behavior has most likely coevolved in conjunction with the obligate endosymbiont to avoid detrimental reproductive phenotypes like hybrid mortality and male sterility in crosses between inter-semispecies (Ehrman 1968; Kim and Ehrman 1998). Here we have evaluated the potential of Wolbachia to trigger assortative mating behavior in $D$. paulistorum towards per se compatible mates under laboratory conditions. Our results suggest that kd-males appear sexually less attractive for their wt-female counterparts in mate choice assays upon manipulation of the native $w$ PauWolbachia titer since they were expressing high SIIs in all assays. Such high SIIs were previously found only between members of different D. paulistorum semispecies (Ehrman 1965; Malogolowkin-Cohen et al. 1965) or between Drosophila species that are sexually isolated from each other (reviewed in Spieth and Ringo 1983; Martin and Hosken 2003; Anderson and Kim 2005; Castrezana and Markow 2008). Our data also indicate that de novo sexual isolation in D. paulistorum under our experimental conditions is transient as eSIIs reverted to random mating around generation $\mathrm{F}_{13}$ post $\mathrm{kd}$ (only $45-57 \%$ homogamy) together with the observed re-colonization of male oenocytes. However, experimental reduction of native D. paulistorum-Wolbachia titers was sufficient to alter males so that they were subsequently rejected by wt-females in the two semispecies tested, at least transiently. Interestingly we observed significant assortative mating between independently established $\mathrm{kd}$-isofemale lines of the same semispecies, a finding most likely caused by drift. In such, heterogeneity of kd isolines could be a result of different temporal and spatial dynamics of Wolbachia recolonization of behavioral important tissues in the individual lines post knockdown. To test this drift hypothesis for kd lines, however, detailed quantitative and qualitative analyses of global symbiont titer levels, but also their in situ tropism and densities will be necessary from multiple staged flies and tissues of the same generation. In our current study, extensive analyses like these were not possible due to limitations of fly material at this time point.

\section{Host pheromonal signatures may be a target for Wolbachia to signal the infection state and to impact mate choice}

In many insects, sexual pheromones serve as recognition cues for mate choice between and within species and are hence important players in reproductive isolation (Coyne et al. 1994; Savarit et al. 1998; Ferveur 2005). Moreover, such cues might even be prone to manipulation by pathogenic bacteria, as recently shown in $D$. melanogaster (Keesey et al. 2017).

In our study, the observed alteration of pheromone blends in kd-males may explain why females prefer wt-mates carrying the intact native profile. This finding is corroborated by studies showing that in lekking sandflies (Lutzomya), female mate choice is influenced by the amount of pheromones released by males before potential mating (Jones and Hamilton 1998; Jones et al. 2000). Another study demonstrated the influence of Wolbachia on host odor-linked mate preference in the terrestrial isopod Armadillidium vulgare (Richard 2017). In $\mathrm{A} 28^{\mathrm{kd}}$ and $\mathrm{O} 11^{\mathrm{kd}}$ males, relative quantities of pheromone compounds were affected differently, suggesting that the quantitative change in at least one of the male-specific components, but possibly also in conjunction with some other non-sex-specific CHCs, might be sufficient to trigger rejection of kd-males by wt-females in choice experiments. Importantly, our findings are in line with a recent study suggesting that Wolbachia can influence pupal communication between females and males in Drosophila melanogaster by modulating CI levels (Pontier and Schweissguth 2015, 2017; but also see; Jacquet et al. 2017). However, as shown earlier, facultative Wolbachia symbionts of $D$. melanogaster adults do not affect mate choice behavior in this system at all, but possibly other gut microbes (Sharon et al. 2010; Ringo et al. 2011; Arbuthnott et al. 2016). Importantly, a very recent study has severely questioned the potential impact of the gut microbiome on reproductive isolation since the microbiome of $D$. melanogaster is not fixed but reported as flexible and environmental determined (Leftwich et al. 2017). In the mutualistic D. paulistorum-Wolbachia system, however, where the endosymbiont is fixed by serving vital but still undetermined functions to their native host (Miller et al. 2010) we suggest that these obligate Wolbachia have also a direct or indirect impact on adult cuticular hydrocarbon (CHC) profiles, where male-specific and sex-unspecific compounds change quantitatively upon Wolbachia-kd in adult males.

The presence of Wolbachia in oenocytes of $\mathrm{O} 11^{\mathrm{wt}}$ males implies a direct or indirect interaction of the symbiont with 
host pheromone production and mate choice behavior as a consequence. The potential effects of the endosymbiont in oenocytes on female pheromone blending, however, await elucidation. If the presence of Wolbachia in male oenocytes is essential to express the semispecies-specific pheromone profile, loss of the symbiont from male oenocytes $\left(\mathrm{F}_{4}\right.$ post $\mathrm{kd}$ ) might explain why pheromone profiles are altered and knockdown males are consequently rejected as mate partners from homogamic wt-females. Based on our mate choice assays, the de novo assortative mating phenotype behavior is transient and results in reversion to a wt-like situation around $\mathrm{F}_{13} / \mathrm{F}_{14}$ post knockdown. Assuming a direct link between Wolbachia tropism in the oenocytes and expression of the male pheromone profile, we expected a recolonization of oenocytes in parallel with reversion to random mating phenotype. We could confirm such recolonization, and thus potentially explain reversion to random mating, in oenocytes of $\mathrm{F}_{13} \mathrm{O} 11^{\mathrm{kd}}$ males. Our finding is particularly interesting in the light of the contrasting situation in D. melanogaster, where Wolbachia do not play a role in mate choice (Sharon et al. 2010; Ringo et al. 2011; Arbuthnott et al. 2016). In our experimental setup, we did not detect Wolbachia in D. melanogaster oenocytes, which most likely explains why the symbiont does not affect mate choice and pheromone expression in this model system (Sharon et al. 2010). Finally, in contrast with the strict neurotropism of obligate Wolbachia to defined brain regions of D. paulistorum, (Strunov et al. 2017) native Wolbachia are randomly dispersed at low densities in D. melanogaster brains (Albertson et al. 2009). However, it remains to be elucidated how Wolbachia manipulate male pheromone expression and female mate choice in D. paulistorum.

To conclude, our combined data strongly imply that artificial reduction of the obligate Wolbachia endosymbiont of D. paulistorum males significantly reduces mating success with homogamic wildtype females belonging to the same semispecies. Although these and earlier findings in D. paulistorum lead to interpretations based on associations rather than causation and their functional and molecular bases are still undetermined, we propose the following model for the potential impact of the $D$. paulistorum endosymbiont on RI and host speciation in this system. In contrast to most facultative Wolbachia-insect associations, where the symbiont is not fixed and does not serve vital host functions, D. paulistorum semispecies have evolved vital mutualistic associations with their endosymbiont (Miller et al. 2010) as well as strict tissue tropisms to reproductive host organs, such as the primordial germline cells of embryos and adult gonads (Miller et al. 2010), but also to defined larval and adult brain regions associated with sexual behavior (Strunov et al. 2017) and pheromone producing oenocytes (this study). As implicated from the results of this study even partial depletions of the mutualist from their primary somatic host targets, such as oenocytes, might directly or indirectly alter pheromone signatures of males, which are no longer accepted as mates from stress-free wt females.

It appears likely that spontaneous symbiont knockdowns might also happen in the wild by stochastic exposure of the host to natural antibiotics or heat stress. This de novo assortative phenotype expressed by females against aberrant homogamic males can significantly disrupt gene flow within populations via premating isolation, at least transiently. As shown earlier, however, Wolbachia-kd males are accepted by kd females, which randomly mate even with heterogamic males under lab conditions (Miller et al. 2010). Under this scenario two sexually isolated reproductive groups would emerge and coexist next to each other. Since population sizes of Wolbachia have dropped significantly upon such external stresses, it seems quite likely that genetic drift (Chrostek et al. 2013; Schneider et al. 2013; Newton et al. 2014) can cause disruptive diversification of earlier-compatible Wolbachia variants that consequently trigger high cytoplasmic incompatibilities plus complete male sterility at postmating levels.

Hence it seems plausible that in Dobzhansky's earlier studies (Dobzhansky and Pavlovsky 1966, 1971, 1975) where spontaneous emergence of strong post mating incompatibilities between long term isolated sub lines of the same $D$. paulistorum semispecies were observed, he had actually detected the final outcome of this symbiotic stress and drift effect, observed in our current experimental study. Planned studies, however, should elucidate the mechanistic basis of Wolbachia-influence on male pheromone production and whether similar scenarios observed under lab conditions also take place in nature.

Acknowledgements Open access funding provided by Austrian Science Fund (FWF). We thank Bertha Inocencio Green and Traude Kehrer for fly work and Dr. Taina Chao for help with analyses of $D$. paulistorum. We also thank the Max Planck Society for supporting this study.

Funding This study was funded by two Grants (P22634-B17, P28255-B22) from the Austrian Science Fund to WJM, and by a Grant (FA0701-9528) from the COST Action to DIS. The Max Planck Society was also supporting this study (TE, MK) and LE was awarded an Eugene and Emily Grant (E2 Grant 331-15).

\section{Compliance with ethical standards}

Conflict of interest Daniela I. Schneider, Lee Ehrman, Tobias Engl, Martin Kaltenpoth, Aurélie Hua-Van, Arnaud Le Rouzic and Wolfgang J. Miller declare that they have no conflict of interest.

Ethical approval For this type of study formal consent is not required. This article does not contain any studies with human participants or animals performed by any of the authors. 
Informed consent Not applicable.

Open Access This article is distributed under the terms of the Creative Commons Attribution 4.0 International License (http://creativeco mmons.org/licenses/by/4.0/), which permits unrestricted use, distribution, and reproduction in any medium, provided you give appropriate credit to the original author(s) and the source, provide a link to the Creative Commons license, and indicate if changes were made.

\section{References}

Aitchinson J (1986) The statistical analysis of compositional data. Monographs on statistics and applied probability. Chapman and Hall Ltd., London

Albertson R, Casper-Lindley C, Cao J, Tram U, Sullivan W (2009) Symmetric and asymmetric mitotic segregation patterns influence Wolbachia distribution in host somatic tissue. J Cell Sci 122:4570-4583

Anderson WW, Kim YK (2005) Sexual isolation between sympatric and allopatric populations of Drosophila pseudoobscura and $D$. persimilis. Behav Genet 35:305-312

Arbuthnott D, Levin TC, Promislow DE (2016) The impacts of Wolbachia and the microbiome on mate choice in Drosophila melanogaster. J Evol Biol 29:461-468

Audsley MD, Ye YH, McGraw EA (2017) The microbiome composition of Aedes aegypti is not critical for Wolbachia-mediated inhibition of dengue virus. PLoS Negl Trop Dis 11(3):e0005426

Blomquist GJ, Bagnères AG (2010) Insect hydrocarbons: biology, biochemistry, and chemical ecology. Cambridge University Press, Cambridge

Bordenstein SR, O'Hara FP, Werren JH (2001) Wolbachia-induced incompatibility precedes other hybrid incompatibilities in Nasonia. Nature 409:707-710

Brownlie JC, Cass BN, Riegler M (2009) Evidence for metabolic provisioning by a common invertebrate endosymbiont, Wolbachia pipientis, during periods of nutritional stress. PLoS Pathog. (4):e1000368

Brucker RM, Bordenstein SR (2012) Speciation by symbiosis. Trends Ecol Evol 27:443-451

Brucker RM, Bordenstein SR (2013) The hologenomic basis of speciation: gut bacteria cause hybrid lethality in the genus Nasonia. Science 341:667-669

Brucker RM, Bordenstein SR (2014) Response to Comment on "The hologenomic basis of speciation: gut bacteria cause hybrid lethality in the genus Nasonia". Science 345:1011

Burla H, Brito da Cunha A, Cordeiro AR, Dobzhansky T, Malogolowkin C, Pavan C (1949) The willistoni group of sibling species of Drosophila. Evolution 3:300-314

Castrezana SJ, Markow TA (2008) Sexual isolation and mating propensity among allopatric Drosophila mettleri populations. Behav Genet 38:437-445

Chandler JA, Turelli M (2014) Comment on "The hologenomic basis of speciation: gut bacteria cause hybrid lethality in the genus Nasonia". Science 345:1011

Chao TH, Ehrman L, Permaul A, Vincent R, Sattaur L, Brandt D (2010) Male-specific cuticular compounds of the six Drosophila paulistorum semispecies: structural identification and mating effect. J Chem Ecol 36:933-942

Chen SJ, Lu F, Cheng JA, Jiang MX, Way MO (2012) Identification and biological role of the endosymbionts Wolbachia in rice water weevil (Coleoptera: Curculionidae). Environ Entomol 41:469-477
Chrostek E, Marialva MS, Esteves SS, Weinert LA, Martinez J, Jiggins F, Teixeira M, L (2013) Wolbachia variants induce differential protection to viruses in Drosophila melanogaster: a phenotypic and phylogenomic analysis. PLoS Genet 9(12):e1003896

Chung H, Carroll SB (2015) Wax, sex and the origin of species: dual roles of insect cuticular hydrocarbons in adaptation and mating. Bioessays 37:822-830

Cooper BS, Ginsberg PS, Turelli M, Matute DR (2017) Wolbachia in the Drosophila yakuba complex: pervasive frequency variation and weak cytoplasmic incompatibility, but no apparent effect on reproductive isolation. Genetics 205:333-351

Coyne JA, Orr HA (2004) Speciation. Sinauer Associates, Sunderland

Coyne JA, Crittenden AP, Mah K (1994) Genetics of a pheromonal difference contributing to reproductive isolation in Drosophila. Science 265:1461-1464

Dedeine F, Vavre F, Fleury F, Loppin B, Hochberg ME, Bouletreau M (2001) Removing symbiotic Wolbachia bacteria specifically inhibits oogenesis in a parasitic wasp. Proc Natl Acad Sci USA 98:6247-6252

Dembeck LM, Böröczky K, Huang W, Schal C, Anholt RR, Mackay TF (2015) Genetic architecture of natural variation in cuticular hydrocarbon composition in Drosophila melanogaster. Elife. https://doi.org/10.7554/eLife.09861

Dobzhansky T, Pavlovsky O (1966) Spontaneous origin of an incipient species in the Drosophila paulistorum complex. Proc Natl Acad Sci USA 55:727-733

Dobzhansky T, Pavlovsky O (1971) Experimentally created incipient species of Drosophila. Nature 230:289-292

Dobzhansky T, Pavlovsky O (1975) Unstable intermediates between Orinocan and Interior semispecies of Drosophila paulistorum. Evolution 29:242-248

Dobzhansky T, Spassky B (1959) Drosophila paulistorum, a cluster of species in statu nascendi. Proc Natl Acad Sci USA 45:419-428

Dodd DMB (1989) Reproductive isolation as a consequence of adaptive divergence in Drosophila pseudoobscura. Evolution 43:1308-1311

Ehrman L (1965) Direct observation of sexual isolation between allopatric and between sympatric strains of the different Drosophila paulistorum races. Evolution 19:459-464

Ehrman L (1968) Antibiotics and infections hybrid sterility in Drosophila paulistorum. Mol Gen Genet 103:218-222

Ehrman L, Parsons PA (1981) Behavior genetics and evolution. McGraw-Hill, New York

Ehrman L, Powell JR (1982) The Drosophila willistoni species group. In: Ashburner M, Carson HL, Thompson JN (eds) The genetics and biology of Drosophila. Academic Press, New York, pp 192-225

Fast EM, Toomey ME, Panaram K, Desjardins D, Kolaczyk ED, Frydman HM (2011) Wolbachia enhance Drosophila stem cell proliferation and target the germline stem cell niche. Science 334:990-992

Ferveur JF (2005) Cuticular hydrocarbons: their evolution and roles in Drosophila pheromonal communication. Behav Genet 35:279-295

Gebiola M, Kelly SE, Hammerstein P, Giorgini M, Hunter MS (2016) "Darwin's corollary" and cytoplasmic incompatibility induced by Cardinium may contribute to speciation in Encarsia wasps (Hymenoptera: Aphelinidae). Evolution 70:2447-2458

Hosokawa T, Koga R, Kikuchi Y, Meng XY, Fukatsu T (2010) Wolbachia as a bacteriocyte-associated nutritional mutualist. Proc Natl Acad Sci USA 107:769-774

Jacquet A, Horard B, Loppin B (2017) Does pupal communication influence Wolbachia-mediated cytoplasmic incompatibility? Curr Biol 27:R55-R56 
Jaenike J, Dyer KA, Cornish C, Minhas MS (2006) Asymmetrical reinforcement and Wolbachia infection in Drosophila. Plos Biol 4(10):e325

Jones TM, Hamilton JGC (1998) A role for pheromones in mate choice in a lekking sandfly. Animal Behav 56:891-898

Jones TM, Balmford A, Quinnell RJ (2000) Adaptive female choice for middle-aged mates in a lekking sandfly. Proc R Soc B 267:681-686

Keesey IW, Koerte S, Khallaf MA, Retzke T, Guillou A, Grosse-Wilde E, Buchon N, Knaden M, Hansson BS (2017) Pathogenic bacteria enhance dispersal through alteration of Drosophila social communication. Nat Commun 8:265

Kernaghan RP, Ehrman L (1970) Antimycoplasmal antibiotics and hybrid sterility in Drosophila paulistorum. Science 169:63-64

Kim YK, Ehrman L (1998) Developmental isolation and subsequent adult behavior of Drosophila paulistorum. IV. Courtship. Behav Genet 28:57-65

Kim YK, Phillips DR, Chao T, Ehrman L (2004) Developmental isolation and subsequent adult behavior of Drosophila paulistorum. VI. Quantitative variation in cuticular hydrocarbons. Behav Genet 34:385-394

Leclerq S, Mian FM, Stanisz AM, Bindels LB, Cambier E, Ben-Amram H, Koren O, Forsythe P, Bienenstock J (2017) Low-dose penicillin in early life induces long-term changes in murine gut microbiota, brain cytokines and behavior. Nat Commun 8:15062

Leftwich PT, Clarke NVE, Hutchings MI, Chapman T (2017) Gut microbiomes and reproductive isolation in Drosophila. Proc Natl Acad Sci USA 114:12767-12772

Leonard J, Ehrman L (1983) Does the rare male advantage result from faulty experimental design? Genetics 104:713-716

Malogolowkin-Cohen C, Simmons AS, Levene H (1965) A study of sexual isolation between certain strains of Drosophila paulistorum. Evolution 19:95-103

Martin OY, Hosken DJ (2003) The evolution of reproductive isolation through sexual conflict. Nature 423:979-982

Martinez J, Ok S, Smith S, Snoeck K, Day JP, Jiggins FM (2015) Should symbionts be nice or selfish? Antiviral effects of Wolbachia are costly but reproductive parasitism is not. PLoS Pathog 11(7):e1005021

Miller WJ, Riegler M (2006) Evolutionary dynamics of $w$ Au-like Wolbachia variants in Neotropical Drosophila species. Appl Environ Microbiol 72:826-835

Miller WJ, Schneider D (2012) Endosymbiotic microbes as adaptive manipulators of arthropod behaviour and natural driving sources of host speciation. In: Hughes D, Brodeur $\mathrm{J} J$, and Thomas $\mathrm{F}$ (eds) Host manipulation by parasites. University Press, Oxford, pp 119-139

Miller WJ, Ehrman L, Schneider D (2010) Infectious speciation revisited: impact of symbiont-depletion on female fitness and mating behavior of Drosophila paulistorum. PLoS Pathog 6(12):e1001214

Moriyama M, Nikoh N, Hosokawa T, Fukatsu T (2015) Riboflavin provisioning underlies Wolbachia's fitness contribution to its insect host. mBio 6(6):e01732-e01715

Mouton L, Henri H, Bouletreau M, Vavre F (2006) Effect of temperature on Wolbachia density and impact on cytoplasmic incompatibility. Parasitology 132(Pt):49-56

Najarro MA, Sumethasorn M, Lamoureux A, Turner TL (2015) Choosing mates based on the diet of your ancestors: replication of nongenetic assortative mating in Drosophila melanogaster. PeerJ 3:e1173

Newton IL, Sheehan, and K. B (2014) Passage of Wolbachia pipientis through mutant Drosophila melanogaster induces phenotypic and genomic changes. Appl Environ Microbiol 81:1032-1037
Nikoh N, Hosokawa T, Moriyama M, Oshima K, Hattori M, Fukatsu T (2014) Evolutionary origin of insect-Wolbachia nutritional mutualism. Proc Natl Acad Sci USA 111:10257-10262

Pannebakker BA, Loppin B, Elemans CP, Humblot L, Vavre F (2007) Parasitic inhibition of cell death facilitates symbiosis. Proc Natl Acad Sci USA 104:213-215

Pfarr KM, Heider U, Schmetz C, Buttner DW, Hoerauf A (2008) The mitochondrial heat shock protein 60 (HSP 60) is up-regulated in Onchocerca volvulus after the depletion of Wolbachia. Parasitology 135:529-538

Poinsot D, Montchamp-Moreau C, Merçot H (2000) Wolbachia segregation rate in Drosophila simulans naturally bi-infected cytoplasmic lineages. Heredity 85:191-198

Pontier SM, Schweissguth F (2015) A Wolbachia-sensitive communication between male and female pupae controls gamete compatibility in Drosophila. Curr Biol 25:2339-2348

Pontier SM, Schweissguth F (2017) Response to "Does pupal communication influence Wolbachia-mediated cytoplasmic incompatibility? Curr Biol 27(2):R55-R56

Reynolds KT, Hoffmann AA (2002) Male age, host effects and the weak expression or non-expression of cytoplasmic incompatibility in Drosophila strains infected by maternally transmitted Wolbachia. Genet Res 80:79-87

Richard F-J (2017) Symbiotic bacteria influence the odor and mating preference of their hosts. Front Ecol Evol. https://doi.org/10.3389/ fevo.2017.00143

Ringo J, Sharon G, Segal D (2011) Bacteria-induced sexual isolation in Drosophila. Fly 5:310-315

Savarit F, Sureau G, Cobb M, Ferveur JF (1998) Genetic elimination of known pheromones reveals the fundamental chemical bases of mating and isolation in Drosophila. Proc Natl Acad Sci USA 96:9015-9020

Schneider DI, Riegler M, Arthofer W, Merçot H, Stauffer C, Miller WJ (2013) Uncovering Wolbachia diversity upon artificial host transfer. PLoS ONE 8(12):e82402

Schneider DI, Parker AG, Abd-Alla AM, Miller WJ (2018) High-sensitivity detection of cryptic Wolbachia in the African tsetse fly (Glossina spp.). BMC Microbiol, in press

Sharon G, Segal D, Ringo JM, Hefetz A, Zilber-Rosenberg I, Rosenberg E (2010) Commensal bacteria play a role in mating preference of Drosophila melanogaster. Proc Natl Acad Sci USA 107:20051-20056

Spieth HT, Ringo JM (1983) Mating behavior and sexual isolation in Drosophila. In: Ashburner M, Carson HL, Thompson JN (eds) The genetics and biology of Drosophila. Academic Press, London, pp 345-384

Strübing U, Lucius R, Hoerauf A, Pfarr KM (2010) Mitochondrial genes for heme-dependent respiratory chain complexes are upregulated after depletion of Wolbachia from filarial nematodes. Int J Parasitol 40:1193-1202

Strunov A, Schneider DI, Alberston R, Miller WJ (2017) Restricted distribution and lateralization of mutualistic Wolbachia in the Drosophila brain. Cell Microbiol. https://doi.org/10.1111/cmi.12639

Teixeira L, Ferreira A, Ashburner M (2008) The bacterial symbiont Wolbachia induces resistance to RNA viral infections in Drosophila melanogaster PLoS Biol 6:2753-2763

Telschow A, Flor M, Kobayashi Y, Hammerstein P, Werren JH (2007) Wolbachia-induced unidirectional cytoplasmic incompatibility and speciation: mainland-island model. PLoS ONE 2(8):e701

Telschow A, Hilgenboecker K, Hammerstein P, Werren JH (2014) Dobzhansky-Muller and Wolbachia-induced incompatibilities in a diploid genetic system. PLoS ONE 9(4):e95488

Turelli M, Lipkowitz JR, Brandvain Y (2014) On the Coyne and Orrigin of species: effects of intrinsic postzygotic isolation, ecological differentiation, $\mathrm{X}$ chromosome size, and sympatry on Drosophila speciation. Evolution 68:1176-1187 
Ueyama M, Chertemps T, Labeur C, Wicker-Thomas C (2005) Mutations in the desat 1 gene reduces the production of courtship stimulatory pheromones through a marked effect on fatty acids in Drosophila melanogaster. Insect Biochem Mol Biol 35:911-920

Weeks AR, Turelli M, Harcombe WR, Reynolds KT, Hoffmann AA (2007) From parasite to mutualist: rapid evolution of Wolbachia in natural populations of Drosophila. PLoS Biol 5(5):e114

Werren JH, Baldo L, Clark ME (2008) Wolbachia: master manipulators of invertebrate biology. Nat Rev Microbiol 6:741-751

Yamada R, Floate K, Riegler M, O’Neill S (2007) Male development time influences the strength of Wolbachia-induced cytoplasmic incompatibility expression in Drosophila melanogaster. Genetics 177:801-808

Ye YH, Seleznev A, Flores HA, Woolfit M, McGraw EA (2017) Gut microbiota in Drosophila melanogaster interacts with Wolbachia but does not contribute to Wolbachia-mediated antiviral protection. J Invertebr Pathol 143:18-25

Zug R, Hammerstein P (2012) Still a host of hosts for Wolbachia: analysis of recent data suggests that $40 \%$ of terrestrial arthropod species are infected. PLoS ONE 7(6): e38544 